\title{
Medication-related problems in older people: how to optimise medication management
}

\author{
CW Wong *
}

\section{A B S T R A C T}

Older patients are at risk of medication-related problems because of age-related physiological changes and multiple medications taken for multiple co-morbidities. The resultant polypharmacy is frequently associated with inappropriate medication use, which in turn contributes to a range of adverse consequences, including geriatric syndromes (eg, falls, cognitive decline, urinary incontinence) and hospitalisation. In addition, medication nonadherence or discrepancies between the medications prescribed and those actually taken by patients, either intentional or unintentional, are prevalent and can lead to treatment failure. A large proportion of adverse drug events are preventable, and medication errors occur most commonly at the stages of prescribing and subsequent monitoring. There are

This article was published on 16 Dec 2020 at www.hkmj.org. a number of strategies to address these issues with the aim of ensuring safe prescribing. Furthermore, deprescribing with withdrawal of medications that are inappropriate or of minimal value for patients is increasingly emphasised for optimising medication management. In general, optimisation of medication management should be patient-centred, considering individual circumstances and preferences to determine the treatment goals or priorities for individual patients, and a multidisciplinary approach is recommended.

\section{Hong Kong Med J 2020;26:510-9}

https://doi.org/10.12809/hkmj208534

CW Wong *, FHKAM (Medicine), FHKCP

Department of Medicine and Geriatrics, Caritas Medical Centre, Kowloon, Hong Kong

* Corresponding author: wong.chitwai@gmail.com

\section{Introduction}

With advances in medicine, new drugs are developed and approved every year for particular diseases and conditions. In addition, evidence-based clinical practice guidelines are being developed to assist clinicians' decisions about the best care for patients with specific diseases or clinical conditions for which medications are frequently recommended. The urge for increased prescribing gives rise to medicationrelated problems, which are particularly problematic in elderly patients because of their tendency to have multiple co-morbidities and age-related changes in pharmacokinetics and pharmacodynamics. The resultant polypharmacy seems to be unavoidable nowadays, and it is often associated with potentially inappropriate medications (PIM) and adverse drug events. Furthermore, medication adherence is insufficient in elderly patients. All of these factors predispose patients to adverse health outcomes, which deviate from the original intention of therapeutic benefit but produce morbidity and mortality with hospitalisation ${ }^{1,2}$ and increase the social health cost.

Appropriate medication management with reduction of polypharmacy, reduction of use of inappropriate medications, and improvement of medication adherence is relevant to optimisation of older patients' care. Because older people are highly heterogeneous in terms of co-morbidities, functional state, and psychosocial aspects, clinical and medication management should be individualised. The principle of prescribing to older people should weigh the clinical benefits against the risks of medication therapies or overprescribing to address the patients' individual care goals, current functioning level, social support, life expectancy, values, and preference.

This article starts with case scenarios in each section to illustrate and discuss the medicationrelated problems of polypharmacy/inappropriate medications, adverse drug events and prescribing cascade, medication non-adherence, and postdischarge medication discrepancy. These are followed by patient-centred measures that recommend prioritisation of treatment, deprescribing, and use of a multidisciplinary approach. Table $1^{3-10}$ summarises the terms mentioned in this article with definitions.

\section{Polypharmacy and potentially inappropriate medications}

\section{Case scenario 1}

An 80-year-old woman had hypertension, diabetes mellitus, and ischaemic heart disease. She had 17 medications on her prescription list: aspirin, famotidine, amlodipine, methyldopa, enalapril, gliclazide, metformin, simvastatin, enalapril, isosorbide, frusemide, potassium chloride, and as-needed drugs (betahistine, chlorphenamine, cocillana, benadryl expectorant, and zopiclone). 
She strongly refused medications tapering during follow-up at an out-patient clinic because of fear of worsening blood pressure control, feet oedema, dizziness, coughing, and insomnia. She was recently admitted because of dizziness and fall, found to have low blood pressure of 108/50 $\mathrm{mm} \mathrm{Hg}$ and a heart rate of 90 beats per minute, mild dehydration with hyperkalaemia (urea $7.8 \mathrm{mmol} / \mathrm{L}$, creatinine $60 \mu \mathrm{mol} / \mathrm{L}$, sodium $144 \mathrm{mmol} / \mathrm{L}$, potassium $4.8 \mathrm{mmol} / \mathrm{L})$ and vitamin $B_{12}$ deficiency $(100 \mathrm{pmol} / \mathrm{L})$.

\section{Case scenario 2}

A 75-year-old man had benign prostatic hyperplasia and was taking terazosin. He developed herpes zoster with postherpetic neuralgia, and amitriptyline was prescribed. He then developed retention of urine.

Multiple co-morbidities are often prevalent among older people. In Hong Kong, older patients attending specialist out-patient clinics had an average of four to five co-morbidities. ${ }^{11}$ With new drugs and clinical guidelines being developed for each disease, the number of medications taken by individual patients is increasing. The mean number of medications prescribed per patient were six and nine in out-patient and in-patient settings, respectively.11-13 Using the concurrent use of five or more daily medications to define polypharmacy, as many as 77.8\% of older patients in Hong Kong had the burden of polypharmacy, which was more than double the corresponding proportion of $32 \%$ from two decades ago, ${ }^{12,14}$ and $11 \%$ took 10 or more medications. ${ }^{11}$

\section{老年人之用藥問題：如何改善及處理 王哲慧}

隨着年䶧增加, 身體功能逐漸衰退, 因疾病而多重用藥或不恰當使用 藥物, 令老年病人面臨藥物不良反應及後果, 這包括老年綜合症（跌 倒、認知能力下降、尿失禁) 和住院。處方的藥物與病患者實際服用 的藥之間有差異是非常普遍的, 這可影響治療的效果。大部份不良藥 物事件是可以預防的, 而用藥錯誤最常見於處方及隨後監測階段。處 理老人藥物問題必須強調精簡處方, 即對症用藥, 減少或停止對病人 用有害多於有益的處方。總的來説, 應以病患者為中心, 考慮他們的 實際情況來制定優先或治療目標。然後才處方用藥, 這是改善藥物處 理的可行方案。

Polypharmacy is positively associated with PIM and subsequent adverse drug events, drug-drug interactions, and drug-disease interactions. .11,14-16 $^{-1}$ Potentially inappropriate medications are not solely attributable to inappropriate prescribing but are also related to changes in the benefits and risks of a medication with time: medications can become inappropriate for a given patient even if they were previously appropriate. Approximately $30 \%$ to $59 \%$ of patients in Hong Kong have been found to be taking at least one inappropriate medication. ${ }^{11-13}$ The most common causes of inappropriateness were medications without clear indications, lack of effectiveness, incorrect dosage, difficult instructions, unacceptable duration of therapy, and high cost in comparison to alternatives of equal efficacy and safety. ${ }^{13}$ Very often, it is difficult to measure the

TABLE I. Terminology and definitions

\begin{tabular}{|c|c|}
\hline Terminology & Definition \\
\hline Adverse drug event & $\begin{array}{l}\text { An adverse drug event is an injury resulting from the use of a drug. It includes harm caused by the drug (adverse } \\
\text { reaction or overdose) and harm from the use of the drug (including dose reduction and discontinuation of drug } \\
\text { therapy). It may also result from medication errors during prescribing, transcribing, dispensing, administering, } \\
\text { adherence, or monitoring of a drug. }\end{array}$ \\
\hline Adverse drug reaction & An adverse drug reaction is harm directly caused by the drug at normal doses during normal use. ${ }^{6}$ \\
\hline Deprescribing & $\begin{array}{l}\text { There is no consensus on the definition. It was proposed as the systematic process of identifying and discontinuing } \\
\text { drugs of which the harms outweigh the benefits within the context of an individual patient's care goals, current level } \\
\text { of functioning, life expectancy, values, and preference. }\end{array}$ \\
\hline Medication adherence & $\begin{array}{l}\text { Medication adherence is the extent to which a patient takes medications as prescribed by the healthcare provider.,4 } \\
\text { Adherence is a preferred term over compliance, as adherence implies that patient is involved in treatment decisions } \\
\text { and has the responsibility to comply with treatment instead of the treatment decision being solely made by the } \\
\text { clinician and the patient passively following. }{ }^{4}\end{array}$ \\
\hline Medication discrepancy & Medication discrepancy is the difference between the medication list and the medications actually taken by patients. \\
\hline Medication reconciliation & $\begin{array}{l}\text { Medication reconciliation is a process for creating the most complete and accurate list by comparing a patient's } \\
\text { medication orders to all of the medications the patient has been taking. This can avoid medication errors such as } \\
\text { omission, duplication, dosing errors, and drug interactions. }{ }^{7}\end{array}$ \\
\hline Polypharmacy & $\begin{array}{l}\text { The definition of polypharmacy is variable. }{ }^{8} \text { The most common is the numerical definition of use of five or more } \\
\text { medications daily. }\end{array}$ \\
\hline $\begin{array}{l}\text { Potentially inappropriate } \\
\text { medication }\end{array}$ & $\begin{array}{l}\text { A potentially inappropriate medication is a drug for which the risk of adverse events outweighs the clinical benefits. } \\
\text { Explicit criteria such as the Beers criteria and implicit evaluations such as Medication Appropriateness Index have } \\
\text { been developed to identify potentially inappropriate medications. }\end{array}$ \\
\hline Prescribing cascade & $\begin{array}{l}\text { A prescribing cascade is the use of one medication to treat the side-effects of another medication when an adverse } \\
\text { drug effect is misidentified as a new condition; thus, a new medication is prescribed for treatment. }{ }^{10}\end{array}$ \\
\hline
\end{tabular}


direct influence of inappropriate medications on the patient and healthcare system. The nonspecific symptoms and geriatric syndromes caused by inappropriate medications include fatigue, dizziness, falls, urinary incontinence, and functional or cognitive decline. These might be disregarded as being related to ageing, making adverse drug events difficult to recognise..$^{15,16}$ Nonetheless, inappropriate medications would potentially increase adverse drug events or reactions with increased morbidity, hospitalisation, and healthcare cost. ${ }^{17-19}$

\section{Screening for potentially inappropriate medications}

Since polypharmacy are difficult to avoid nowadays, the practical way to deal with is to enhance appropriate use of medications with reduction of PIM. Criteria and evaluation processes have been developed to screen for PIM in older people. Most are explicit criteria based on trial evidence, systematic reviews, expert panel suggestions, and consensus evaluation with the aims of improving medication appropriateness and minimising adverse drug events and subsequent hospitalisation. The most widely used explicit prescribing criteria are the Beers criteria and the Screening Tool of Older Person potentially inappropriate Prescriptions (STOPP)/Screening Tool to Alert doctors to the Right Treatment (START) criteria.

The Beers criteria were designed for use in people aged 65 years or older in ambulatory, acute, and institutionalised settings but not for those receiving hospice or palliative care. ${ }^{20}$ The Beers criteria have undergone review and been updated regularly since first being published in 1991. The most updated version, the Beers 2019 criteria ${ }^{21}$ lists PIMs to be avoided in five categories: (1) Drugs and drug classes to avoid; (2) Drugs and drug classes to avoid in certain diseases or syndromes; (3) Drugs to be used with caution; (4) Drug-drug interactions that should be avoided; and (5) Drugs to be avoided or dosage reduced in cases with kidney disease. Each criterion stated is supplemented by the rationale for the recommendation, level of evidence, and strength of the recommendation.

The STOPP/START criteria provide prescribing guidance tailored for older people aged 65 years or older. ${ }^{22}$ Like the Beers criteria, the STOPP criteria comprise a list of PIMs. In addition, a list of potential prescribing omissions (START criteria) alert clinicians about appropriate and indicated prescribing. Instead of listing the offending drugs, the STOPP/START criteria outline clinical circumstances with each criterion to address the drug or drug class that is deemed to be inappropriate or drugs that should be considered, so they are considered to be more relevant in clinical practice. The STOPP/START criteria have also been updated to maintain their clinical relevance: the latest edition (version 2) was published in 2015. ${ }^{23}$

These explicit criteria provide only evidencebased references but do not address individual patients' circumstances, such as co-morbidities and preference. Therefore, they cannot replace clinical judgement about patient-centred decisions but can alert clinicians to potential instances of inappropriate medication use.

Implicit evaluation, in contrast, is judgementbased and focused on patients rather than drugs or diseases. The Medication Appropriateness Index is one set of implicit tool and is frequently used in research. ${ }^{24}$ It includes 10 items to determine the appropriateness of a given medication: indication, effectiveness, correct dosage, practical direction, drug-drug interactions, drug-disease interactions, duplication, acceptable duration, and expense. "Yes" or "No" is applied for each item in which "Yes" scores 0 whereas "No" scores from 1 to 3 depending on its importance in the assessment of the appropriateness of a given drug with indication and effectiveness are given most weigh. A total score is then generated with higher scores indicating more inappropriate medications. Although these evaluation processes are patient-centred and address the entire medication regimen, their applicability is limited by the fact that they are time-consuming and dependent on the clinician's knowledge and experience.

\section{Remarks}

Scenario 1 illustrated polypharmacy with the adverse outcomes of dizziness and fall. The inappropriate medications prescribed were those with no clear indications or questionable effectiveness, or for the treatment of a drug adverse reaction, such as frusemide (STOPP criteria) for feet oedema, which was possibly related to the adverse effects of amlodipine; benadryl and cocillana for cough, which were possibly related to the adverse effects of enalapril; and betahistine for dizziness, which was possibly related to methyldopa (STOPP and Beers criteria) and vitamin $B_{12}$ deficiency as a result of longterm metformin intake. Medications were adjusted by replacing enalapril with losartan, replacing methyldopa and amlodipine with metoprolol for blood pressure control and ischaemic heart disease (START criteria), and adding a vitamin $\mathrm{B}_{12}$ supplement. The patient was tapered off frusemide, potassium chloride, and all as-needed medications.

In scenario 2, prescribing amitriptyline (which has strong anticholinergic properties) to an elderly man with benign prostatic hypertrophy is considered to be inappropriate (Beers and STOPP criteria), as it could precipitate urinary retention, and there are alternatives with fewer anticholinergic effects. For example, gabapentin can be chosen for postherpetic neuralgia. 


\section{Adverse drug events and prescribing cascade}

\section{Case scenario 3}

A 70-year-old man had behavioural psychological symptoms of dementia and was prescribed memantine, sertraline, quetiapine, and lorazepam. Because of fall with back pain, paracetamol and tramadol were prescribed. He developed nausea and vomiting, and then metoclopramide was given. Later, he developed fever, restlessness, and limb rigidity. Serotonin syndrome as a result of concomitant use of sertraline, tramadol, and metoclopramide was suspected.

Adverse drug events are common in clinical practice. Large-scale studies have found overall rates of adverse drug events of 50.1 per 1000 person-years in ambulatory older people and 1.89 per 100 person-months in institutionalised elderly residents. ${ }^{25,26}$ The most commonly implicated agents were cardiovascular drugs in the ambulatory setting and antipsychotics in the institutional setting, which might be related to the frequent use of these drugs in those corresponding settings. Accordingly, the most common types of adverse events were electrolyte/ renal, gastrointestinal tract, and haemorrhage events in ambulatory patients, whereas neuropsychiatric events (oversedation, confusion, hallucinations, delirium) predominated in the institutional setting. Up to $51 \%$ of the observed adverse drug events were preventable, and serious, life-threatening and fatal events were more likely to be preventable than were less severe events. ${ }^{25,26}$ The errors associated with those preventable events most commonly occurred at the stages of prescribing and monitoring. Prescribing errors included wrong dosage, significant drug interactions, and wrong choice of drugs (eg, using drugs with significant anticholinergic effects instead of safer alternatives). Monitoring errors refer to inadequate laboratory monitoring, delayed response or failure to respond to signs and symptoms, and/or laboratory evidence of toxicity.

Adverse drug events or reactions may precipitate a prescribing cascade. Prescribing cascade occurs when adverse drug events are mistaken as a new medical condition and leads to addition of new drugs for treatment. ${ }^{10}$ It places patients at risk of developing additional adverse drug events because of the potentially unnecessary treatment. Adverse consequences of prescribing cascade include polypharmacy and its associated adverse event as in Case 1 (see Case 1 remarks), and exacerbation of the harmful effects of adverse drug reactions as in Case 3, serotonin syndrome resulted from the use of serotonin reuptake inhibitors together with tramadol and metoclopramide. In addition to the drugs involved in Cases 1 and 3 (amlodipine, angiotensin- converting enzyme inhibitor, serotonin reuptake inhibitor, and tramadol), other common drugs implicated in prescribing cascade are cholinesterase inhibitors which cause urinary incontinence with subsequent oxybutynin added, non-steroidal antiinflammatory drugs which cause or exacerbate hypertension with antihypertensive agent added, and antipsychotic agents which cause extrapyramidal sign with levodopa or anticholinergic added. ${ }^{27}$ They are largely preventable provided that clinicians are aware of this during the prescribing process.

\section{Preventing adverse drug events and prescribing cascade}

Provided that a significant proportion of adverse drug events and common sources of error are preventable, adverse drug events are amenable to prevention strategies. Computerised order entry is widely used nowadays to alert prescribers about the drug dosage, need for dose adjustment according to renal function, potential drug interactions, or allergic reactions, and this significantly reduces medication errors. ${ }^{28}$ However, this cannot replace clinical judgements about relevant indications, correct drug choices, and simplification of medication regimens. Regular review to obtain an updated medication list is good practice, especially when a new prescription or change in prescription is instituted. Whenever a new symptom occurs, assessment to rule out adverse effects from currently taken medications to prevent a 'prescribing cascade', or adding drugs to treat other drugs' adverse effects, should be considered. Non-pharmacological therapies could be effective alternatives to replace some psychoactive medications. ${ }^{29}$ The development of a systematic approach based on patient-centred care to facilitate decision-making about prescribing certain medications to frail, elderly patients (eg, anticoagulants) and subsequent monitoring is anticipated. Furthermore, enhancement of surveillance and reporting systems for adverse drug events with subsequent analysis and correction of the underlying systematic faults could achieve significant error reduction. ${ }^{30}$

\section{Remarks}

In scenario 3, the series of adverse drug events and the serious medical consequence of serotonin syndrome was preventable if the prescribing cascade had been broken by minimising medications for the behavioural psychological symptoms of dementia, such as stopping quetiapine or lorazepam for fall risk at the initial stage or stopping tramadol to treat the adverse drug reaction of nausea and vomiting instead of giving metoclopramide at a later stage.

\section{Medication adherence}

\section{Case scenario 4}

A 76-year-old man had paroxysmal supraventricular 
tachycardia, for which he had been prescribed sotalol, and iatrogenic Cushing syndrome, for which he was on hydrocortisone replacement. He was admitted for a supraventricular tachycardia attack. He admitted that he did not take sotalol because of fatigue and low heart rate and took hydrocortisone only occasionally because of facial puffiness.

\section{Case scenario 5}

A 79-year-old woman lived alone and was referred to a community nurse for medication management. Many drug stocks were found in her home. She was suspected to have cognitive impairment on initial assessment.

Poor medication adherence is common in clinical practice, with a $50 \%$ adherence rate observed among patients with chronic conditions. ${ }^{3}$ Poor medication adherence is even more problematic in elderly people because they may have decreased functionality and cognitive impairment. Because of the differences in measurement methods used and the settings of the studied populations, the prevalence of medication non-adherence among elderly patients has varied widely in local studies (9\%-54\%). ${ }^{31-33}$ Medication non-adherence leads to drug waste and treatment failure, with resultant hospitalisation and increased healthcare cost. It may also prompt inappropriate increases in drug dosage, addition of or changes to more potent drugs, and increased risk of adverse drug events if it is unrecognised and regarded as poor response to treatment.

There are many ways to assess medication adherence, such as measuring medication or their metabolite levels in blood, using questionnaires or self-reports, and pill counting. Nonetheless, the simplest and most direct method is asking the patient nonjudgmentally about how often they miss doses and encouraging them to talk about their difficulties with medication management. ${ }^{4}$ Barriers to poor medication adherence are multifactorial and can generally be categorised into prescriber-related (eg, poor communication or relationship with patients, lack of time for patient education), patient-related (eg, poor knowledge, fear of adverse reactions, depression, diminished physical or mental capacity), medicationrelated (eg, polypharmacy, complexity of medication regimen), and poor social support. ${ }^{3,34,35}$ Common factors related to poor medication adherence in studies have included adverse drug events, ${ }^{32,33,35}$ complicated drug regimen, ${ }^{32,33,35,36}$ recent changes in medication regimen, ${ }^{37}$ and multiple morbidities or self-perceived poor health. ${ }^{31,35,36}$ Because both cognitive impairment and depression are prevalent among elderly patients, and these conditions can impede functionality and thus medication management, these two conditions should be looked for in older patients with poor medication adherence. ${ }^{31,35,36}$

\section{Improving medication adherence}

As poor medication adherence is often multifactorial, a multidimensional approach is required. In general, such an approach includes patient education, enhancing clinician-patient communication, improving medication regimens, and facilitating social support. Providing education to the patient and their family members or caregivers on medicationand disease-related information, indications and adverse reactions of the medications prescribed, and how to handle the regimen is effective for improving adherence. ${ }^{38}$ Besides, enhancing communication by listening to the patient or caregiver's concerns and formulating a compromised treatment plan can encourage adherence. ${ }^{4}$ Furthermore, encouraging the patient to participate in disease management, such as self-monitoring of blood pressure or blood glucose, can also enhance adherence. ${ }^{4}$ Simplification and regular review of the medication regimen should be emphasised. ${ }^{31,38}$ Older patients with suspicion of cognitive impairment or depression should be assessed for management. Family members of patients with cognitive impairment, mood disorders, or decreased functionality are encouraged to assist in medication management. ${ }^{31,32}$ For those with poor family support, social support from, eg, a community nursing service to assist in packing medications with use of medication boxes or charts can also be helpful. $^{32,38}$ Reinforcement of the above strategies and assessment of adherence should be performed continuously to maintain adherence.

\section{Remarks}

In scenario 4, adverse drug reactions resulted in poor medication adherence. After education and explanation about his medical condition and medication indications, and after his concerns were addressed, the patient agreed to take hydrocortisone and resumed low-dose sotalol with regular review at follow-up clinic.

In scenario 5, cognitive impairment impeded proper drug management. Patients with poor social support, poor disease control, and many drug stocks at home should have a high index of suspicion. The drug regimen was simplified to once/day, and the patient was referred for cognitive assessment, management, and social support.

\section{Post-hospital discharge medication discrepancies}

\section{Case scenario 6}

An 80-year-old woman complained of dizzy spells, and she had a blood pressure of $87 / 39 \mathrm{~mm} \mathrm{Hg}$ and a pulse of 50 beats per minute at follow-up clinic. She had recently been hospitalised for congestive heart failure, and her medications were adjusted (atenolol 
was replaced by carvedilol, and ramipril and frusemide were added). However, she did not notice that the medications had been adjusted and took all of the previous medications together with the newly prescribed medications.

Sometimes, it is not the patient's intention not to follow the medication instructions, but they may not notice or may misunderstand the changes in their medication regimen. Such errors often occur at the time of hospital discharge, as hospital admission typically results in adjustments to medication regimens. Discrepancies between the medications listed on discharge instructions and the medications actually taken by patients were found in up to half of patients following hospital discharge. ${ }^{39,40}$ Older patients are particularly at risk, with fewer than $10 \%$ of community-dwelling older patients adhering completely to their discharge medication lists in one study. ${ }^{41}$ Medication discrepancies include addition/ duplication or omission of medications and changes to dosing or frequency. This might endanger patients' health because of adverse drug events or suboptimal disease control. One study found that $14 \%$ of older patients with medication discrepancies were rehospitalised at 30 days after hospital discharge. ${ }^{42}$

The discharge process is often criticised for its contribution to medication discrepancy. Poor clinician-patient communication, the lack of or incomplete review of medication regimen, or failure to inform the patient about medication changes upon discharge are often blamed as causes. ${ }^{43}$ In addition, inaccurate discharge medication instructions, such as duplication, omission, incorrect dosage or frequency of medications, and unclear prescribing instructions are commonly encountered. ${ }^{40,42,44}$ Discharge medication lists that are not integrated with medications the patient took from other specialties before admission may cause confusion as to whether the patient should continue to take those prior medications or adjust their dosages after discharge. Patients at high risk of postdischarge medication discrepancy include those with depression, ${ }^{39}$ impaired cognitive function or low medication literacy (ie, difficulty understanding medication-related information), ${ }^{39,40}$ and those who receive multiple medications or complicated regimens. ${ }^{41,42}$

\section{Minimising post-discharge medication discrepancy}

Improvement of the hospital discharge process is the first and most important step to improve medication adherence and reduce preventable post-hospitalisation complications. Medications reconciliation to construct an integrated discharge medication list, which combines medications adjusted during hospitalisation and those from other specialties, is recommended. ${ }^{45}$ In addition, reminders to the involved clinicians from other departments about the changes to medications previously prescribed by them are suggested. Counselling and education for patients and their families or caregivers about the new regimen of medications with focus on medication changes from pre-admission and high-risk medications (eg, warfarin and insulin) could promote adherence and medication safety after discharge. ${ }^{46}$ Post-discharge surveillance by phone contact with patients to address post-discharge problems or answer questions has been found to be beneficial. ${ }^{45}$ Arrangements for early follow-up can help with monitoring posthospitalisation medication adherence, adverse effects, and prescribing mistakes.

\section{Remarks}

Medication incidents similar to those in scenario 6 could be avoided with better communication highlighting the adjusted medications upon discharge.

\section{Prioritisation of disease management}

\section{Case scenario 7}

A 60-year-old man had metastatic lung carcinoma and opted for palliative care. Other medical history included diabetes mellitus, hypertension, and cerebrovascular disease. He had cachexia, pain, dyspnoea, and poor oral intake. Medications included morphine, metoclopramide, senokot, enalapril, metformin, gliclazide, simvastatin, aspirin, and pantoprazole.

Patient-centred care has increasingly emphasised addressing the needs of individual patients to maintain their quality of life and functioning. ${ }^{45}$ The goal of care should be individualised, taking into account the disease's impact on both the patient's short- and longterm health, the patient's circumstances, and their preference. Patient-centred care identifies the patient's clinically dominant condition to determine the priority of care. This can guide medication use towards the area most important to the patient and reduce or stop medications that are less meaningful to their health status. In scenario 6, a patient with multiple co-morbidities had been diagnosed with metastatic carcinoma and had a limited life expectancy. Both the patient and their family opted for palliative care (goal of care), and their main concerns were pain and shortness of breath (clinical dominant condition). Proper control of these distressing symptoms should be the priority. In addition to non-pharmacological therapy, medications should be adjusted for symptomatic relief. Medications for other chronic conditions, such as diabetes mellitus 
and cerebrovascular disease, should be minimised, as the potential benefits would likely not be observed, but there would be increased drug interactions and adverse events (eg, hypoglycaemia, poor appetite, bleeding).

\section{Deprescribing}

\section{Case scenario 8}

A 90-year-old woman with right middle cerebral artery infarction was discharged to a residential home. She was bedbound, non-communicable, and totally dependent. Her medications included warfarin, amlodipine, simvastatin, lansoprazole, donepezil, haloperidol, and quetiapine.

Deprescribing is increasingly considered as a part of good clinical practice. Through the process of medication review to withdraw medications that are no longer appropriate or to taper medications to the minimum effective dosage, the benefits and risks of medications can be balanced according to the patient's current health status. Deprescribing is particularly relevant to patients with the burden of polypharmacy or changing clinical conditions. The evidentiary base for deprescribing in older people is growing. Systematic reviews have demonstrated that carefully selecting patients to undergo planned medications withdrawal had no detrimental effects in a substantial proportion of older people. ${ }^{47-49}$ Common drug classes studied in medication withdrawal trials are antihypertensive agents, benzodiazepines, and psychotropic agents. The benefits of discontinuation of these medications is not limited to polypharmacy reduction but also include reduced fall risk and improved cognition and psychomotor function. ${ }^{47-49}$ Although deprescribing is generally regarded as feasible and safe, fear of rebound or return of symptoms and exacerbation of underlying conditions are the major barriers to prescribing. There are practical guides and algorithms to assist with the deprescribing process. ${ }^{5,50,51}$ All highlight that it is a supervised process. Table 2 shows the key steps to deprescribing.

Besides the general approach to deprescribing, there is medication class-based guidance on how to taper particular medications. There are evidencebased guidelines that provide the reasons for and benefits of deprescribing an identified medication, recommendations on how to taper or stop, the period and symptoms to monitor, non-medication approaches for management of symptoms, and instructions if symptoms relapse. ${ }^{52,53}$ The medication classes considered as high priority for deprescribing in older patients are those with high prevalence of use or overtreatment, significant adverse effects, other effective treatment options available, or those that are easy to stop. These medication classes include antipsychotics, statins, benzodiazepines, proton pump inhibitors, nonsteroidal antiinflammatory drugs, furosemide, antihypertensive agents, antihyperglycaemic agents, cholinesterase inhibitors, and memantine..$^{51-54}$

Patients or caregivers who are reluctant or disagree with medications cessation are common. Such attitudes negatively influence the success of deprescribing. The reasons against medications cessation include patients' perceptions that the medications are necessary or beneficial and their fears of worsening clinical conditions or withdrawal effects, especially if they had previous bad experiences with medication cessation. ${ }^{55}$ Another barrier is the limited consultation time and lack of support from clinicians. ${ }^{55}$ A stepwise approach with time given for shared decision-making about deprescribing is reasonable. ${ }^{51}$ Such an approach starts with patient or caregiver education on the purpose of deprescribing, including exploration of and addressing their concerns. Then, options should be provided with respect to medication tapering, non-pharmacological interventions, and monitoring for adverse withdrawal effects, and reassurance should be given that the discontinued medications can be restarted if needed. A multidisciplinary approach with the clinician being supported by other healthcare professionals can relieve time pressure during consultations. Patients with depression and anxiety disorders may need treatment for their psychiatric conditions before they can participate in deprescribing.

TABLE 2. Key steps to deprescribing

\footnotetext{
- Obtain a complete medication list and ask the patient about their adherence or any prescribed medications they do not take and the reason.

- Perform medication review to identify potential medications that can be discontinued or tapered. These include medications without clear indications, lack of efficacy, medications for which the symptoms or conditions have resolved, those of which the adverse effects outweigh the benefits, prophylactic medications in patients with limited life expectancy, medications that patient would like to stop, and medications with complex dosing regimens.

- Communicate with the patient to decide on a cessation regimen, such as the order and time frame of discontinuation. It is suggested to begin with medications that have the lowest benefit-to-harm ratio and the lowest likelihood of the adverse withdrawal reaction of disease rebound syndrome.

- Support and monitor patients for any adverse effects or withdrawal symptoms upon discontinuation.
} 


\section{Remarks}

The patient in scenario 8 was non-communicable and totally dependent. Anticoagulants and simvastatin, which no longer provided cardiovascular/ cerebrovascular benefits, and donepezil, which no longer provided cognitive benefits, were tapered off. Haldol and quetiapine were also tapered off because of the patient's lack of disturbing behaviour.

\section{Multidisciplinary team approach}

A multidisciplinary team approach is recommended to optimise medication management and treatment decisions, minimise adverse drug effects, enhance medication safety, and promote medication adherence. $^{45,56}$

\section{Clinician}

The clinician plays a central role in prescribing and the subsequent medication-related problems. The following points are recommended to improve clinicians' medication management for older patients:

- Think about the indications, the potential benefits and adverse effects, and the patient's capability to follow instructions before prescribing. It is often easier to start medications than withdraw them.

- Avoid prescribing cascades. Be alert to whether the patient's medical complaints could be related to drugs' adverse effects. Instead of adding additional drugs to treat adverse drug effects, potentially offending medications should be withdrawn.

- Provide information to the patient whenever starting a medication.

- Simplify the patient's drug regimen.

- Regularly review the patient's medication regimen, especially when the patient's condition changes.

- Improve communication with patients. Liberally ask them about any problems with the drugs taken, adherence, and adverse effects and adjust the medication regimen accordingly.

\section{Pharmacist}

The role of the pharmacist in the healthcare system is expanding from dispensing service to direct patient care. Pharmacists can help with medication-related problems in different settings. ${ }^{13,57-59}$ Polypharmacy and inappropriate medications: the pharmacist can check the appropriateness of medications to make recommendations for clinicians; Non-adherence: the pharmacist can check the patient's medication adherence or discrepancy, provide counselling, identify the patient's difficulties, and communicate with clinicians to modify the medication regimen. Pharmacists provide both in-patient and out-patient service, the latter in the form of pharmacist-led drug compliance clinics, and their services further extend to the community through public-private partnerships.

Although the results of studies on the efficacy of clinical pharmacy service are equivocal, ${ }^{58}$ pharmacists' positive impact cannot be denied, as those equivocal results are probably related to the complexity of pharmacists' interventions and the lack of an evaluation standard in studies. Nonetheless, a recent local study on a pharmacist-led medication review programme for hospitalised elderly patients that included medication reconciliation, medication review, and medication counselling showed significantly reduced numbers of inappropriate medications and unplanned hospital admissions. ${ }^{13}$ Another local study also demonstrated a positive impact of pharmacists on identifying, resolving, and preventing medication-related problems. ${ }^{59}$

\section{Nurse}

Besides administering medications, nurses are also involved in medication care for older patients in the following ways:

- Nurses record any relevant information about the patient to make suggestions in treatment decision-making.

- Nurses provide support in the community through home visits or phone calls to those who lack of social support and during the postdischarge period and arrange further support if needed.

- Nurses observe, monitor, and document parameters, symptoms, or adverse drug reaction, and then they communicate with clinicians for management.

- Nurses carry out medication management by checking the medication list and medication adherence and tidying up the drug stock and storage. They use pill boxes and drug calendars to remind patients about drug intake.

- Nurses provide education and empower patients in medication management.

\section{Conclusion}

Numerous studies have shown that medicationrelated problems (eg, polypharmacy, inappropriate medication, adverse drug events, medication nonadherence, and medication discrepancy) are common in older patients. Strategies or interventions such as screening tools for inappropriate medications, deprescribing, and multidisciplinary approaches have been introduced to optimise medication management. However, helping patients to take medications safely and effectively is still challenging. Very often, we are aware of the problem, but it is difficult to alter or deal with, as there are multiple barriers (eg, pressure from patients/caregivers, short consultation time). Thus, in addition to continuous 
education, reminding clinicians about appropriate prescribing, regular review, and medication regimen adjustment, public education to promote the rational use of medications is important. Continuing to review and address the effects of deficiencies in the healthcare system on medication safety could lead to a reduction in medication-related problems with time.

\section{Author contributions}

The author contributed to the concept or design of the study, acquisition of the data, analysis or interpretation of the data, drafting of the manuscript, and critical revision of the manuscript for important intellectual content. The author had full access to the data, contributed to the study, approved the final version for publication, and takes responsibility for its accuracy and integrity.

\section{Conflicts of interest}

The author has disclosed no conflicts of interest.

\section{Funding/support}

This research received no specific grant from any funding agency in the public, commercial, or not-for-profit sectors.

\section{References}

1. Lazarou J, Pomeranz BH, Coret RN. Incidence of adverse drug reactions in hospitalized patients: a meta-analysis of prospective studies. JAMA 1998;279:1200-5.

2. Davies EC, Green CF, Taylor S, Williamson PR, Mottram DR, Pirmohamed M. Adverse drug reactions in hospital inpatients: prospective analysis of 3695 patient-episodes. PLoS One 2009;4:e4439.

3. World Health Organization. Adherence to long term therapies: evidence for action. 2003. Available from: https://apps.who.int/iris/bitstream/ handle/10665/42682/9241545992.pdf. Accessed 23 Nov 2020.

4. Osterberg L, Blaschke T. Adherence to medication. N Engl J Med 2005;353:487-97.

5. Scott IA, Hilmer SN, Reeve E, et al. Reducing inappropriate polypharmacy: the process of deprescribing. JAMA Intern Med 2015;175:827-34.

6. VA Centre for Medication Safety, VHA Pharmacy Benefits Management Strategic Healthcare Group, Medical Advisory Panel. Adverse drug events, adverse drug reactions, medications error. Frequently asked questions. November 2006. Available from: https://www. pbm.va.gov/PBM/vacenterformedicationsafety/tools/ AdverseDrugReaction.pdf. Accessed 23 Nov 2020.

7. The Joint Commission. National patient safety goals effective July 2020 for the ambulatory health care program. Available from: https://www.jointcommission.org/-/ media/tjc/documents/standards/national-patient-safetygoals/2020/npsg_chapter_ahc_jul2020.pdf. Accessed 23 Nov 2020.

8. Masnoon N, Shakib S, Kalish-Ellett L, Caughey GE. What is polypharmacy? A systematic review of definitions. BMC Geriatr 2017;17:230.

9. Corsonello A, Pranno L, Garasto S, Fabietti P, Bustacchini S, Lattanzio F. Potentially inappropriate medications in elderly hospitalized patients. Drugs Aging 2009;26 Suppl 1:31-9.

10. Rochon PA, Gurwitz JH. Optimising drug treatment for elderly people. The prescribing cascade. BMJ 1997;315:1096-9.

11. Lam DP, Mak CF, Chan SM, Yao RW, Leung SS, You JH. Polypharmacy and inappropriate prescribing in elderly Hong Kong Chinese patients. J Am Geriatr Soc 2010;58:203-5.

12. Lam MP, Cheung BM, Wong IC. Prevalence of potentially inappropriate prescribing among Hong Kong older adults: a comparison of the Beers 2003, Beers 2012, and screening tool of older person's prescriptions and screening tool to alert doctors to right treatment criteria. J Am Geriatric Soc 2015;63:1471-2.

13. Chiu P, Lee A, See T, Chan F. Outcomes of a pharmacistled medication review programme for hospitalised elderly patients. Hong Kong Med J 2018;24:98-106.

14. Ko CF, Ko PS, Tsang ML. A survey on the polypharmacy and use of inappropriate medication in a geriatric outpatient clinic. J HK Geriatr Soc 1996;7:28-31.

15. Maher RL, Hanlon J, Hajjar ER. Clinical consequence of polypharmacy in elderly. Expert Opin Drug Saf 2014;13:5765.

16. Hajjar ER, Cafiero AC, Hanlon JT. Polypharmacy in elderly patients. Am J Geriatr Pharmacother 2007;5:345-51.

17. Onda M, Imai H, Takada Y, Fujii S, Shono T, Nanaumi Y. Identification and prevalence of adverse drugs events caused by potentially inappropriate medication in homebound elderly patients: a retrospective study using a nationwide survey in Japan. BMJ Open 2015;5:e007581.

18. Fu Az, Liu GG, Christensen DB. Inappropriate medication use and health outcomes in the elderly. J Am Geriatr Soc 2002;52:1934-9.

19. Laroche ML, Charmes JP, Nouaille Y, Picard N, Merle L. Is inappropriate medication use a major cause of adverse drug reactions in the elderly? Br J Clin Pharmacol 2007;63:17786.

20. American Geriatrics Society 2015 Beers Criteria Update Expert Panel. American Geriatrics Society 2015 updated Beers Criteria for potentially inappropriate medication use in older adults. J Am Geriatr Soc 2015;63:2227-46.

21. American Geriatrics Society 2019 Beers Criteria Update Expert Panel. American Geriatrics Society 2019 updated AGS Beers Criteria for potentially inappropriate medication use in older adults. J Am Geriatr Soc 2019;67:674-94.

22. Gallagher P, Ryan C, Byrne S, Kennedy J, O’Mahony D. STOPP (Screening Tool of Older Person's Prescriptions) and START (Screening Tool to Alert doctors to Right Treatment). Consensus validation. Int J Clin Pharmacol Ther 2008;46:72-83.

23. O'Mahony D, O'Sullivan D, Byne S, O'Connor MN, Ryan C, Gallagher P. STOPP/START criteria for potentially inappropriate prescribing in older people: version 2. Age Ageing 2015;44:213-8.

24. Hanlon JT, Schmader KE, Samsa GP, et al. A method for assessing drug therapy appropriateness. J Clin Epidemiol 1992;45:1045-51.

25. Gurwitz JH, Field TS, Harrold LR, et al. Incidence and preventability of adverse drug events among older persons in the ambulatory setting. JAMA 2003;289:1107-16.

26. Gurwitz JH, Field TS, Avorn J, et al. Incidence and preventability of adverse drug events in nursing homes. Am J Med 2000;109:87-94. 
27. Kalisch LM, Caughey GE, Roughead EE, Gilbert AL. The prescribing cascade. Aust Prescr 2011;34:162-6.

28. Bates DW, Leape LL, Cullen DJ, et al. Effect of computerised physician order entry and a team intervention on prevention of serious medication error. JAMA 1998;280:1311-6.

29. de Oliverira AM, Radanovic M, de Mello PC, et al. Nonpharmacological interventions to reduce behavioural and psychological symptoms of dementia: a systematic review. Biomed Res Int 2015;2015:218980.

30. Leape LL. Error in medicine. JAMA 1994;272:1851-7.

31. Leung DY, Bai X, Leung AY, Lou BC, Chi I. Prevalence of medication adherence and its associated factors among community-dwelling Chinese older adults in Hong Kong. Geriari Gerontol Int 2015;15:789-96.

32. Lam PW, Lum CM, Leung MF. Drug non-adherence and associated risk factors among Chinese geriatric patients in Hong Kong. Hong Kong Med J 2007;13:284-92.

33. Chong CK, Chan JC, Chang S, Yuen YH, Lee SC, Critchley JA. A patient compliance survey in a general medical clinic. J Clin Pharm Ther 1997;22:323-6.

34. Hale LS, Calder DR. Managing medication nonadherence. In: Muma RD, Lyons BA, editors. Patient Education: a Practical Approach. 2nd ed. Boston, MA: Jones \& Barlett Learning; 2012: 41-7.

35. Yap AF, Thirumoorthy T, Kwan YH. Systematic review of the barriers affecting medication adherence in older adults. Geriatric Gerontol Int 2016;16:1093-101.

36. Smaje A, Weston-Clark M, Raj R, Orlu M, Davis D, Rawle M. Factors associated with medication adherence in older patients: a systematic review. Aging Med (Milton) 2018;1:245-66.

37. Barber N, Parsons J, Clifford S, Darracott R, Horne R. Patients' problems with new medication for chronic conditions. Qual Saf Health Care 2004;13:172-5.

38. Wilhelmsen NC, Eriksson T. Medication adherence intervention and outcomes: an overview of systematic reviews. Eur J Hosp Pharm 2019;26:187-92.

39. Mixon AS, Myers AP, Leak CL, et al. Characteristics associated with post-discharge medications errors. Mayo Clin Proc 2014;89:1041-51.

40. Lindquist LA, Go L, Fleisher J, Jain N, Friesema E, Baker DW. Relationship of health literacy to intentional and unintentional non-adherence of hospital discharge medications. J Gen Intern Med 2012;27:173-8.

41. Mulhem E, Lick D, Varugese J, Barton E, Ripley T, Haveman J. Adherence to medications after hospital discharge in the elderly. Int J Family Med 2013;2013:901845.

42. Coleman EA, Smith JD, Raha D, Min SJ. Posthospital medication discrepancies: prevalence and contributing factors. Arch Intern Med 2005;165:1842-7.

43. Forster AJ, Murff HJ, Peterson JF, Gandhi TK, Bates DW. The incidence and severity of adverse events affecting patient after discharge from the hospital. Ann Intern Med 2003;138:161-7.

44. Caleres G, Modig S, Midlöv P, Chalmers J, Bondesson A. Medication discrepancies in discharge summaries and associated risk factors for elderly patients with many drugs. Drugs Real World Outcomes 2020;7:53-62.

45. National Institute for Health and Care Excellence, UK
Government. Medicines optimisation: the safe and effective use of medicine to enable the best possible outcomes. NICE guideline [NG5]. 2015. Available from: https://www.nice.org.uk/guidance/ng5/chapter/1Recommendations\#medicines-related-models-oforganisational-and-cross-sector-working. Accessed 23 Nov 2020.

46. Kripalani S, Roumie CL, Dala AK, et al. Effect of a pharmacist intervention on clinically important medication errors after hospital discharge: a randomized controlled trial. Ann Intern Med 2012;157:1-10.

47. Iyer S, Naganathan V, McLachlan AJ, Le Couteur DG. Medication withdrawal trials in people aged 65 years and older: a systematic review. Drugs Aging 2008;25:1021-31.

48. van der Cammen TJ, Rajkumar C, Onder G, Sterke CS, Petrovic M. Drug cessation in complex older adults: time for action. Age Ageing 2014;43:20-5.

49. Declercq T, Petrovic M, Azermai M, et al. Withdrawal versus continuation of chronic antipsychotic drugs for behavioural and psychological symptoms in older people with dementia. Cochrane Database Syst Rev 2013;(3):CD007726.

50. Page AT, Potter K, Clifford R, Etherton-Beer C. Deprescribing in older people. Maturitas 2016;91:115-34.

51. NHSDerbyandDerbyshire. ClinicalCommissioningGroup. Deprescribing: a practical guide. NHS 2019. Available from: http://www.derbyshiremedicinesmanagement.nhs. uk/assets/Clinical_Guidelines/clinical_guidelines_front_ page/Deprescribing.pdf. Accessed 23 Nov 2020.

52. McGrath K, Hajjar ER, Kumar C, Hwang C, Salzman B. Deprescribing: a simple method for reducing polypharmacy. J Fam Pract 2017;66:436-45.

53. Deprescribing.org. Deprescribing guidelines and algorithms. Available from: https://deprescribing.org/ resources/deprescribing-guidelines-algorithms/. Accessed 23 Nov 2020.

54. Farrell B, Tsang C, Raman-Wilms L, Irving H, Conklin J, Pottie K. What are priorities for deprescribing for elderly patients? Capturing the voice of practitioners: a modified delphi process. PLoS One 2015;10:e122246.

55. Reeve E, To J, Hendrix I, Shakib S, Roberts MS, Wiese MD. Patient barriers to and enablers of deprescribing: a systematic review. Drug Aging 2013;30:793-807.

56. Topinková E, Baeyens JP, Michel JP, Lang PO. Evidencebased strategies for the optimization of pharmacotherapy in older people. Drugs Aging 2012;29:477-94.

57. Bonetti AF, Reis WC, Mendes AM, et al. Impact of pharmacist-led discharge counselling on hospital readmission and emergency department visits: a systematic review and meta-analysis. J Hosp Med 2020;15:52-9.

58. Renaudin P, Boyer L, Esteve MA, Bertault-Peres P, Auquier P, Honore S. Do pharmacist-led medication reviews in hospitals help reduce hospital readmission? A systematic review and meta-analysis. Br J Clin Pharmacol 2016;82:1660-73.

59. Chung AY, Anand S, Wong I, et al. Improving medication safety and diabetes management in Hog Kong: a multidisciplinary approach. Hong Kong Med J 2017;23:15867. 